\title{
Multi-objective based economic environmental dispatch with stochastic solar-wind-thermal power system
}

\author{
Surender Reddy Salkuti \\ Department of Railroad and Electrical Engineering, Woosong University, Republic of Korea
}

\begin{abstract}
Article Info
Article history:

Received Jul 30, 2019

Revised Mar 22, 2020

Accepted Apr 3, 2020

\section{Keywords:}

Economic dispatch

Environmental dispatch

Meta-heuristic algorithms

Multi-objective optimization

Renewable energy sources

Uncertainty

ABSTRACT

This paper presents an evolutionary based technique for solving the multi-objective based economic environmental dispatch by considering the stochastic behavior of renewable energy resources (RERs). The power system considered in this paper consists of wind and solar photovoltaic (PV) generators along with conventional thermal energy generators. The RERs are environmentally friendlier, but their intermittent nature affects the system operation. Therefore, the system operator should be aware of these operating conditions and schedule the power output from these resources accordingly. In this paper, the proposed EED problem is solved by considering the nonlinear characteristics of thermal generators, such as ramp rate, valve point loading (VPL), and prohibited operating zones (POZs) effects. The stochastic nature of RERs is handled by the probability distribution analysis. The aim of proposed optimization problem is to minimize operating cost and emission levels by satisfying various operational constraints. In this paper, the single objective optimization problems are solved by using particle swarm optimization (PSO) algorithm, and the multi-objective optimization problem is solved by using the multi-objective PSO algorithm. The feasibility of proposed approach is demonstrated on six generator power system.
\end{abstract}

Copyright (C) 2020Institute of Advanced Engineering and Science. All rights reserved.

\section{Corresponding Author:}

Surender Reddy Salkuti, Department of Railroad and Electrical Engineering, 17-2, Woosong University, Jayang-dong, Dong-gu, Daejeon-34606, Republic of Korea. Email: surender@wsu.ac.kr

\section{INTRODUCTION}

The integration of renewable energy resources (RERs) has enhanced the complexity of power system operation due to inherent uncertainties associated with these types of power generation sources. Due to the rising concern of carbon emission, pollution and oil depletion problem, the demand for renewable power is growing rapidly. Some of the advantages of electric power generated from these RERs are low or no fuel cost, reduced environmental effects compared to fossil fuels and non-depletable resource base. However, they have relatively high capital cost, uneven geographic distribution, intermittent or uncertain nature of power production [1]. The aim of operation of power system is to meet load demand at optimum operating cost, while maintaining safety, reliability and continuity of service. Economy of operation of power system can be achieved when generating units in the system share load to minimize overall cost of generation [2].

Proper power system operation is crucial for a power system to return maximum profit on capital invested. Constantly increasing prices for fuel, supplies and maintenance compelled the power companies to maintain reasonable relation between the cost of power generated and cost of delivering the power to consumers [3]. The cost of energy produced depends on two factors, i.e., fixed and running costs. The fixed cost is independent of plant operation, and it consists of capital cost of power plant, interest on capital, taxes and insurance, salaries of management and clerical staff, and depreciation. Whereas, the running cost varies proportional to the electric energy produced and it consists of cost of fuel, operation cost of the plant in terms of 
salaries and maintenance cost. Traditional/conventional optimization techniques cannot be applied directly for solving because of prohibited zones (discontinuities) in the incremental cost curve. The efficient use of available fuel is growing in importance, because most of the fuel used represents irreplaceable natural resources [4].

An economic environmental dispatch (EED) problem of solar-wind-hydro-thermal generation system with battery energy storage is solved in [5] by using non-dominated sorting genetic algorithm-II. A stochastic dynamic economic dispatch (ED) for low-carbon power dispatching problem is proposed in [6]. The objective of reference [7] is to present the impact of power systems on operating cost and emission including wind energy generators. An EED problem based many objective problem framework is proposed in [8]. Trade-offs between economical environmental impacts of solar-wind-thermal power generation system by using multi-objective model is proposed in [9]. A modified harmony search echnique to solve EED problem for microgrid with RERs is proposed in [10]. An EED problem including solar, wind and small-hydro power is solved in Reference [11].

The solution methodologies presented in the literature do not consider prohibited zone, ramp rate and valve point loading (VPL) effects of conventional thermal generators, therefore these solutions does not include actual operating conditions. Optimization deals with the problem of finding a feasible solution over a set of possible solutions for the given objective function. From the literature survey, it is clear that there is a need for solving the multi-objective based EED problem in a power system with conventional thermal generators along with RERs such as wind and solar PV generators. The non-convex and discontinuous characteristics of thermal generators, i.e., ramp rate limits, VPL and POZs effects are considered in this paper. In this work, the intermittent nature of wind and solar PV powers is handled by the system operator (SO) through Weibull distribution function. Because of this intermittency, the actual output of wind and solar PV generators is going to differ from scheduled one. Therefore, the SO determines the risk due to over-estimation/under-estimation of wind and solar PV powers. In this paper, two objectives, i.e., operating cost and amount of emission release minimizations are optimized by using multi-objective particle swarm optimization (MO-PSO) algorithm. The effectiveness of proposed EED approach has been tested on six unit test system.

\section{PROBLEM FORMULATION OF EED}

\subsection{Economic dispatch (ED) objective}

The ED objective considered in this work is the operating cost (OC), and it consists of costs due to conventional thermal, wind and solar PV generators, and also the costs due to over and under-estimations of wind and solar PV power generations. This ED objective function can be expressed as [12], minimize,

$$
\begin{aligned}
& O C=\sum_{i=1}^{N_{G}} C_{i}\left(P_{G i}\right)+\sum_{j=1}^{N_{W}}\left[C_{W j}\left(P_{W j}\right)+C_{p, W j}\left(P_{W j}^{a v g}-P_{W j}\right)+C_{r, W j}\left(P_{W j}^{a v g}-P_{W j}\right)\right] \\
& +\sum_{k=1}^{N_{S}}\left[C_{S k}\left(P_{S k}\right)+C_{p, S k}\left(P_{S k}^{a v g}-P_{S k}\right)+C_{r, S k}\left(P_{S k}^{a v g}-P_{S k}\right)\right]
\end{aligned}
$$

First term is the quadratic cost function of conventional thermal generating units, and it can be expressed as,

$$
C_{i}\left(P_{G i}\right)=a_{i}+b_{i} P_{G i}+c_{i} P_{G i}^{2}
$$
minimize,

This fuel cost minimization function with valve point loading (VPL) effect can be expressed as,

$$
C_{i}\left(P_{G i}\right)=\sum_{i=1}^{N_{G}}\left[a_{i}+b_{i} P_{G i}+c_{i} P_{G i}^{2}+\left|d_{i} \times \sin \left(e_{i} \times\left(P_{G i}^{\min }-P_{G i}\right)\right)\right|\right]
$$

Second term is direct cost function for the scheduled wind power, and it is given by,

$$
C_{W j}\left(P_{W j}\right)=d_{j} P_{W j}
$$


Third term is penalty cost function of wind power, which accounts under-estimation of wind power. This function is used to find the excess power it might be produced than the scheduled one, and this penalty cost function can be expressed by using [13],

$$
C_{p, W j}\left(P_{W j}^{a v g}-P_{W j}\right)=K_{P, j}\left(P_{W j}^{a v g}-P_{W j}\right)=K_{p, j} \int_{P_{W j}}^{P_{r, j}}\left(p-P_{W j}\right) f_{p}(p) d W
$$

Fourth term is the over-estimation cost of wind power, which is due to available wind power being less than scheduled one (i.e., over-estimation of wind power). The cost function can be expressed as [14],

$$
C_{r, W j}\left(P_{W j}-P_{W j}^{a v g}\right)=K_{r, j}\left(P_{W j}-P_{W j}^{a v g}\right)=K_{r, j} \int_{0}^{P_{W j}}\left(P_{W j}-p\right) f_{p}(p) d W
$$

Fifth term accounts the direct cost associated with solar PV power, and it can be expressed as,

$$
C_{S k}\left(P_{S k}\right)=x_{k} P_{S k}
$$

Sixth term is under-estimation cost of solar PV power, which is due to available solar PV power is more than scheduled solar PV power. The penalty cost function due to excess power can be expresses as,

$$
C_{p, S k}\left(P_{S k}^{a v g}-P_{S k}\right)=K_{P, k}\left(P_{S k}^{a v g}-P_{S k}\right)=K_{p, j} \int_{P_{S k}}^{P_{r, j}}\left(p-P_{S k}\right) f_{p}(p) d S
$$

Last term is over-estimation cost function of solar PV power, which is due to available solar PV power is less than scheduled one. This cost function can be expressed using,

$$
C_{r, S k}\left(P_{S k}-P_{S k}^{a v g}\right)=K_{r, j}\left(P_{S k}-P_{S k}^{a v g}\right)=K_{r, j} \int_{0}^{P_{S k}}\left(P_{S k}-p\right) f_{p}(p) d S
$$

\subsection{Emission dispatch objective}

Here, the emission due to nitrogen oxides, carbon oxides and sulfur oxides is considered, and the objective function is formulated as minimization of total emission release (E). It can be expressed as [15], minimize,

$$
E=\sum_{i=1}^{n}\left(\alpha_{i}+\beta_{i} P_{G i}+\gamma_{i} P_{G i}^{2}\right)
$$

\subsection{Constraints}

The proposed optimization problem is solved by the following equality and inequality constraints.

\subsubsection{Power balance constraint}

This constraint can be expressed using [16],

$$
E=\sum_{i=1}^{n}\left(\alpha_{i}+\beta_{i} P_{G i}+\gamma_{i} P_{G i}^{2}\right)
$$

The power output from wind energy generators can be expressed as,

$$
0 \leq P_{W j} \leq P_{W j}^{\max }
$$


The power output from solar PV generators can be expressed as,

$$
0 \leq P_{W j} \leq P_{W j}^{\max }
$$

\subsubsection{Power generation constraints}

The conventional thermal power generation limits by including the ramp rate limits [17] can be expressed as,

$$
\max \left(P_{G i}^{\min }, P_{G i}^{0}-D R_{i}\right) \leq P_{G i} \leq \min \left(P_{G i}^{\max }, P_{G i}^{0}+U R_{i}\right)
$$

\subsubsection{Effects of POZs}

To avoid the prohibited zone of operation, the power output of conventional thermal generating units is adjusted depending upon the loading conditions. Mathematically, the POZs of a thermal generator can be expressed as [18],

$$
P_{G i} \in\left\{\begin{array}{c}
P_{G i}^{\min } \leq P_{G i} \leq P_{G i, 1}^{l} \\
P_{G i, k-1}^{u} \leq P_{G i} \leq P_{G i, k}^{l} \quad\left(k=2, \ldots, N_{z i}\right) \\
P_{G i, N_{z i}}^{u} \leq P_{G i} \leq P_{G i}^{\max }
\end{array}\right.
$$

\section{MODELING OF WIND AND SOLAR PV SYSTEMS}

\subsection{Modeling of wind speed and power distribution}

Nowadays, most attention has been focused on the probability distribution functions (PDFs) for wind energy applications because of its greater flexibility and simplicity. In this work, the Weibull PDF is used for modeling the wind speed, which is then, transformed to wind power distribution to utilize it in proposed EED model. The power output from wind generator can be expressed by the following equations [12],

$$
\begin{aligned}
& p=0, \quad \text { for } v<v_{i} \text { and } v>v_{o} \\
& p=p_{r} * \frac{\left(v-v_{i}\right)}{\left(v_{r}-v_{i}\right)}, \quad \text { for } v_{i} \leq v \leq v_{r} \\
& p=p_{r}, \quad \text { for } v_{r} \leq v \leq v_{o}
\end{aligned}
$$

The wind power can be modeled as a continuous distribution function with Weibull PDF, and it is expressed as $[19,20]$,

$$
f_{p}(p)=\frac{k\left(v_{r}-v_{i}\right)}{c^{k} * p_{r}}\left[v_{i}+\frac{p}{p_{r}}\left(v_{r}-v_{i}\right)^{k-1}\right] \exp \left[-\left[\frac{v_{i}+\frac{p}{p_{r}}\left(v_{r}-v_{i}\right)}{c}\right]^{k}\right]
$$

\subsection{Modeling of solar PV system and uncertainty}

Power output from solar PV unit can be expressed as [21],

$$
P_{P V}=\left\{\begin{array}{lr}
P_{S}^{r}\left(\frac{G^{2}}{G_{s t d} R_{c}}\right) & \text { for } 0<G<R_{c} \\
P_{S}^{r}\left(\frac{G}{G_{s t d}}\right) & \text { for } G>R_{c}
\end{array}\right.
$$

The hourly solar PV irradiation at a particular location follows a bimodal distribution, and this distribution function can be represented as a linear combination of two unimodal distribution functions. In this paper, the unimodal function is modeled by using Weibull PDF, and it is represented by [21],

$$
f(G)=\omega\left(\frac{k_{1}}{c_{1}}\right)\left(\frac{G}{c_{1}}\right)^{k_{1}-1} e^{-\left(\frac{G}{c_{1}}\right)^{k_{1}}}+(1-\omega)\left(\frac{k_{2}}{c_{2}}\right)\left(\frac{G}{c_{2}}\right)^{k_{2}-1} e^{-\left(\frac{G}{c_{2}}\right)^{k_{2}}}
$$

where $\omega$ is weight factor $(0<\omega<\infty) . c_{1}, c_{2}, k_{1}$ and $k_{2}$ are scale and shape factors, respectively. 


\section{SINGLE AND MULTI-OBJECTIVE OPTIMIZATION}

In this paper, the single objective optimization (SOO) problems, i.e., economic dispatch and environmental dispatch are solved by using particle swarm optimization (PSO) [22, 23]. The multi-objective EED optimizes both the economic and emission dispatch objectives simultaneously. The principle of an ideal MOO is:

- Step 1: Determine the multiple trade-off optimal solutions with a wide range of values for the considered objectives.

- Step 2: Select one of the solutions as best-compromised solution by using higher level data.

As mentioned earlier, in this work, the Multi-Objective Particle Swarm Optimization (MO-PSO) is used for solving proposed multi-objective based EED problem. The detailed description of MO-PSO algorithm has been presented in the references [24, 25].

\section{RESULTS AND DISCUSSION}

The effectiveness of proposed EED methodology has been examined on six generating units system. Among these 6 generating units, generator 1 is considered as wind energy generator, and generator 2 is considered as solar PV generator. The minimum and maximum power outputs of wind and solar PV plants are considered as $0 \mathrm{MW}$ and $100 \mathrm{MW}$, respectively. For thermal generating units, the ramp rate and POZs limits are taken from [26]. Table 1 presents the generator power, ramp rate and POZs limits of thermal generators.

Table 1. Generators power, ramp rate and POZs limits of thermal generating units

\begin{tabular}{ccccccc}
\hline Generator Number & $P_{G i}^{\min }(\mathrm{MW})$ & $P_{G i}^{\max }(\mathrm{MW})$ & $P_{G i}^{0}(\mathrm{MW})$ & $U R_{i}(\mathrm{MW})$ & $D R_{i}(\mathrm{MW})$ & Prohibited Zones $(\mathrm{MW})$ \\
\hline 3 & 35 & 225 & 114 & 55 & 65 & {$[105.117][165.177]$} \\
4 & 35 & 210 & 114 & 50 & 90 & {$[55.85][115.130]$} \\
5 & 130 & 325 & 150 & 80 & 120 & {$[80.90][230.255]$} \\
6 & 125 & 315 & 125 & 80 & 120 & {$[80.90][230.255]$} \\
\hline
\end{tabular}

All the case studies are performed on 6 generating units system with the load demands of 400 MW and $900 \mathrm{MW}$. The proposed SOO problems are solved by using PSO, and the obtained results are also compared with GA and EGA [27]. The proposed MOO based EED problem is solved by using MO-PSO algorithm. Figure 1 depicts the flow chart of PSO for solving SOO problems of operating cost and amount of emission minimizations.

In this paper, 3 different cases are simulated, and they are

- Case 1: Solving only economic dispatch (ED) as a SOO problem.

- Case 2: Solving only emission dispatch as a SOO problem.

- Case 3: Solving EED problem as a MOO problem.

\subsection{Simulation results for case 1}

In this case, ED problem is solved as a SOO problem by using PSO, and the obtained results are also compared with GA and EGA. Here, generator 1 is considered as a wind energy generator, and generator 2 is considered as solar PV generator [28]. ED problem with operating cost minimization as an objective function is solved by considering load demands of $400 \mathrm{MW}$ and $900 \mathrm{MW}$. Table 2 depicts the optimum control variables and objective function values for case 1 . When the load demand $\left(P_{D}\right)$ is $400 \mathrm{MW}$, the obtained optimum operating costs using GA, EGA and PSO algorithms are $25632.3 \mathrm{Rs} / \mathrm{h}, 25314.2 \mathrm{Rs} / \mathrm{h}$ and $25107.1 \mathrm{Rs} / \mathrm{h}$, respectively. Whereas, the amount of emission released using GA, EGA and PSO algorithms are $202.10 \mathrm{~kg} / \mathrm{h}, 201.82 \mathrm{~kg} / \mathrm{h}$ and $201.60 \mathrm{~kg} / \mathrm{h}$, respectively. When the $P_{D}$ is $900 \mathrm{MW}$, then the optimum operating cost obtained by using GA, EGA and PSO algorithms is 51614.4 Rs/h, 51532.3 Rs/h and 51413.6 Rs/h, respectively.

\subsection{Simulation results for case 2}

In this case, the emission minimization objective is optimized independently by using GA, EGA and PSO algorithms [29]. Table 3 depicts the optimum control variables and objective function values for case 2. In this case, the emission dispatch problem is solved by considering the two demands, i.e., $400 \mathrm{MW}$ and $900 \mathrm{MW}$. For $400 \mathrm{MW}$ demand, the optimum amount of emission released by using GA, EGA and PSO algorithms is $180.22 \mathrm{~kg} / \mathrm{h}, 179.61 \mathrm{~kg} / \mathrm{h}$ and $179.32 \mathrm{~kg} / \mathrm{h}$, respectively. For $900 \mathrm{MW}$ demand, the optimum amount of emission released by using GA, EGA and PSO algorithms is $605.42 \mathrm{~kg} / \mathrm{h}, 604.91 \mathrm{kxg} / \mathrm{h}$ and $604.31 \mathrm{~kg} / \mathrm{h}$, respectively. 
Read thermal, wind, solar PV generators cost data, emission data, P limits, ramp rate limits, prohibited zones, B coefficient, demand, PSO parameters etc.

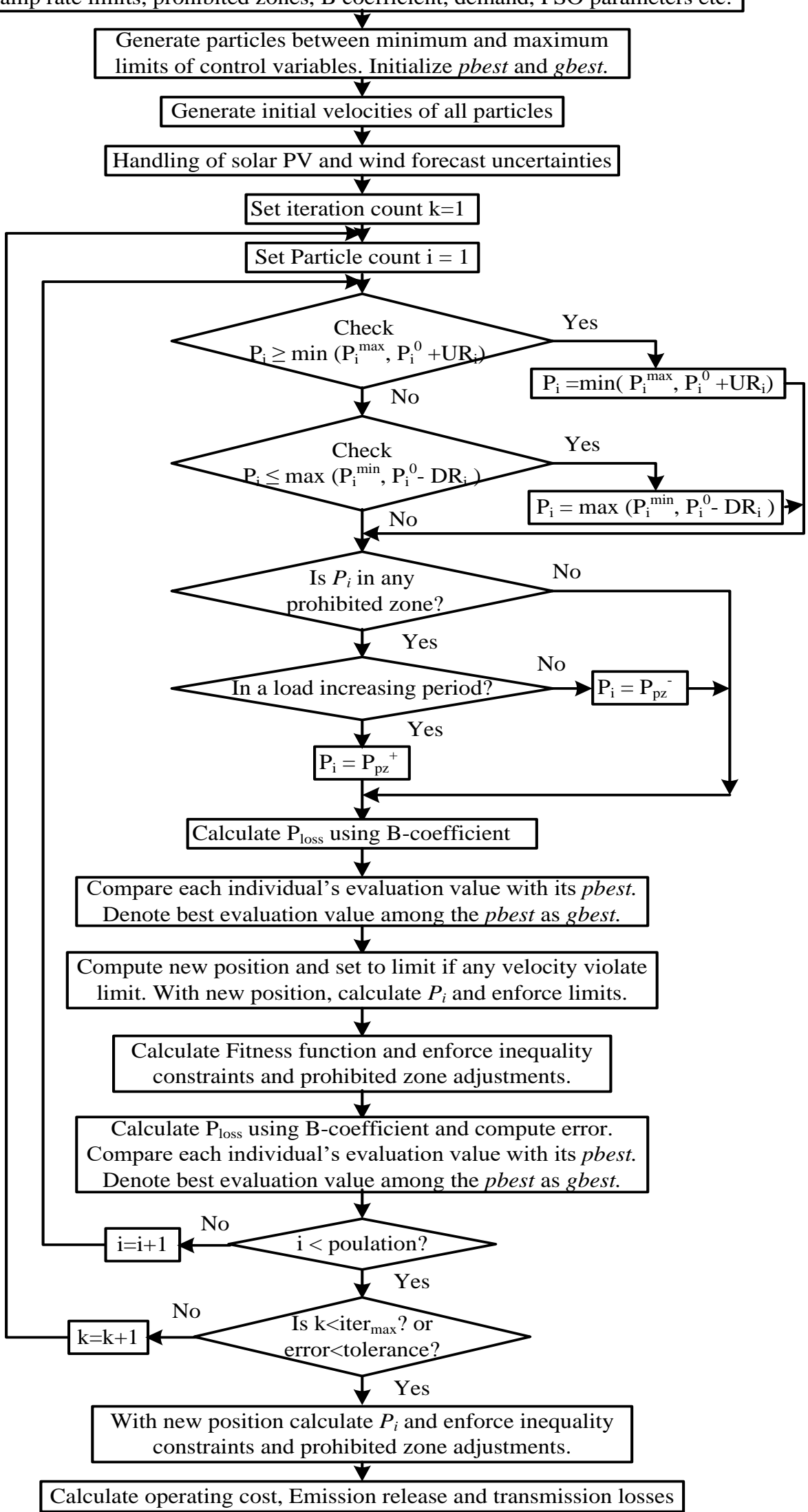

Figure 1. Flow chart of PSO for solving the EED problem 
Table 2. Optimum control variables and objective function values for case 1

\begin{tabular}{ccccccc}
\hline $\begin{array}{c}\text { Power outputs and } \\
\text { objective functions }\end{array}$ & \multicolumn{2}{c}{ Power Demand $\left(P_{D}\right)=400 \mathrm{MW}$} & \multicolumn{3}{c}{ Power Demand $\left(P_{D}\right)=900 \mathrm{MW}$} \\
\hline Generator 1 $\left(P_{W}\right)(\mathrm{MW})$ & 18.9 & 18.8 & 18.6 & 75.6 & 75.3 & 75.8 \\
Generator 2 $\left(P_{S}\right)(\mathrm{MW})$ & 15.5 & 15.8 & 15.8 & 77.9 & 77.8 & 78.2 \\
Generator 3 $\left(P_{G 3}\right)(\mathrm{MW})$ & 50.1 & 50.4 & 50.3 & 179 & 179 & 179 \\
Generator 4 $\left(P_{G 4}\right)(\mathrm{MW})$ & 55 & 55 & 55 & 157.7 & 158.0 & 157.1 \\
Generator 5 $\left(P_{G 5}\right)(\mathrm{MW})$ & 143.0 & 142.4 & 142.7 & 230 & 230 & 230 \\
Generator 6 $\left(P_{G 6}\right)(\mathrm{MW})$ & 125 & 125 & 125 & 210 & 210 & 210 \\
Power loss $\left(P_{\text {loss }}\right)(\mathrm{MW})$ & 7.5 & 7.4 & 7.4 & 30.2 & 30.1 & 30.1 \\
Operating cost $(\mathbf{R s} / \mathbf{h})$ & $\mathbf{2 5 6 3 2 . 3}$ & $\mathbf{2 5 3 1 4 . 2}$ & $\mathbf{2 5 1 0 7 . 1}$ & $\mathbf{5 1 6 1 4 . 4}$ & $\mathbf{5 1 5 3 2 . 3}$ & $\mathbf{5 1 4 1 3 . 6}$ \\
Emission $(\mathrm{kg} / \mathrm{h})$ & 202.10 & 201.82 & 201.60 & 680.3 & 679.5 & 679.2 \\
\hline
\end{tabular}

Table 3. Optimum control variables and objective function values for case 2

\begin{tabular}{ccccccc}
\hline $\begin{array}{c}\text { Power outputs and } \\
\text { objective functions }\end{array}$ & \multicolumn{2}{c}{ Power Demand $\left(P_{D}\right)=400 \mathrm{MW}$} & \multicolumn{4}{c}{ Power Demand $\left(P_{D}\right)=900 \mathrm{MW}$} \\
\hline Generator 1 $\left(P_{W}\right)(\mathrm{MW})$ & 45.8 & 46.2 & 46.4 & 85.6 & 86.2 & 86.4 \\
Generator 2 $\left(P_{S}\right)(\mathrm{MW})$ & 40.3 & 41.2 & 41.3 & 80.9 & 81.6 & 81.8 \\
Generator 3 $\left(P_{G 3}\right)(\mathrm{MW})$ & 32 & 30.8 & 30.4 & 179.2 & 175.0 & 173.9 \\
Generator 4 $\left(P_{G 4}\right)(\mathrm{MW})$ & 35 & 35 & 35 & 160.3 & 162.5 & 162.8 \\
Generator 5 $\left(P_{G 5}\right)(\mathrm{MW})$ & 130 & 130 & 130 & 220.4 & 220.9 & 221.3 \\
Generator 6 $\left(P_{G 6}\right)(\mathrm{MW})$ & 125 & 125 & 125 & 205 & 205 & 205 \\
Power loss $\left(P_{\text {loss }}\right)(\mathrm{MW})$ & 8.1 & 8.2 & 8.1 & 31.4 & 31.2 & 31.2 \\
Operating cost $(\mathrm{Rs} / \mathrm{h})$ & 28896.4 & 28801.3 & 28750.9 & 57403.9 & 57184.6 & 57014.5 \\
Emission $(\mathbf{k g} / \mathbf{h})$ & $\mathbf{1 8 0 . 2 2}$ & $\mathbf{1 7 9 . 6 1}$ & $\mathbf{1 7 9 . 3 2}$ & $\mathbf{6 0 5 . 4 2}$ & $\mathbf{6 0 4 . 9 1}$ & $\mathbf{6 0 4 . 3 1}$ \\
\hline
\end{tabular}

From the above results, it is clear that when the operating cost is optimum then the emission released has been deviated from optimum. Similarly, when the amount of emission released is optimum, and then the operating cost has deviated from optimum. Hence, there is a need for solving the two objectives (i.e., operating cost and emission minimizations) simultaneously.

\subsection{Simulation results for case 3}

Table 4 presents the optimum control variables and objective function values for case 3 . In the present case, both the objectives, i.e., operating cost and emission release are optimized simultaneously [30]. For $P_{D}$ of $400 \mathrm{MW}$, Figure 2(a) depicts the Pareto optimal front of operating cost and emission release objectives by using MO-PSO algorithm. Here, the fuzzy min-max methodology is used to find the best-compromised solution. In this case, the obtained best-compromised solution has operating cost of $26120.32 \mathrm{Rs} / \mathrm{h}$, and amount of emission release of $189.71 \mathrm{~kg} / \mathrm{h}$. For $P_{D}$ of $900 \mathrm{MW}$, Figure 2(b) depicts the Pareto optimal front of operating cost and emission release objectives by using MO-PSO algorithm. For this load demand, the obtained optimum values of operating cost and emission values by using MO-PSO are $53332.4 \mathrm{Rs} / \mathrm{h}, 622.1 \mathrm{~kg} / \mathrm{h}$, respectively.

From the below test cases, it is observed that by using the PSO algorithm, the obtained operating cost and emission release are optimum compared to GA and EGA algorithms. By using MO-PSO algorithm, both the objectives, i.e., operating cost and emission released are optimized simultaneosly and the best-compromised solution has been determined by using fuzzy min-max approach.

Table 4. Optimum control variables and objective function values for case 3

\begin{tabular}{ccc}
\hline Power outputs and objective functions & $\begin{array}{c}P_{D}=400 \mathrm{MW} \\
\text { MO-PSO }\end{array}$ & $\begin{array}{c}P_{D}=900 \mathrm{MW} \\
\text { MO-PSO }\end{array}$ \\
\hline Generator 1 $\left(P_{W}\right)(\mathrm{MW})$ & 30.6 & 81.3 \\
Generator 2 $\left(P_{S}\right)(\mathrm{MW})$ & 28.5 & 80.7 \\
Generator 3 $\left(P_{G 3}\right)(\mathrm{MW})$ & 41.8 & 180.5 \\
Generator 4 $\left(P_{G 4}\right)(\mathrm{MW})$ & 46.4 & 264.8 \\
Generator 5 $\left(P_{G 5}\right)(\mathrm{MW})$ & 130.0 & 93.1 \\
Generator 6 $\left(P_{G 6}\right)(\mathrm{MW})$ & 130.5 & 230.2 \\
Power loss $\left(P_{\text {loss }}\right)(\mathrm{MW})$ & 7.8 & 30.6 \\
Operating cost $(\mathbf{R s} / \mathbf{h})$ & $\mathbf{2 6 1 2 0 . 3 2}$ & $\mathbf{5 4 4 0 9 . 6}$ \\
Emission $(\mathbf{k g} / \mathbf{h})$ & $\mathbf{1 8 9 . 7 1}$ & $\mathbf{6 4 2 . 4 5}$ \\
\hline
\end{tabular}




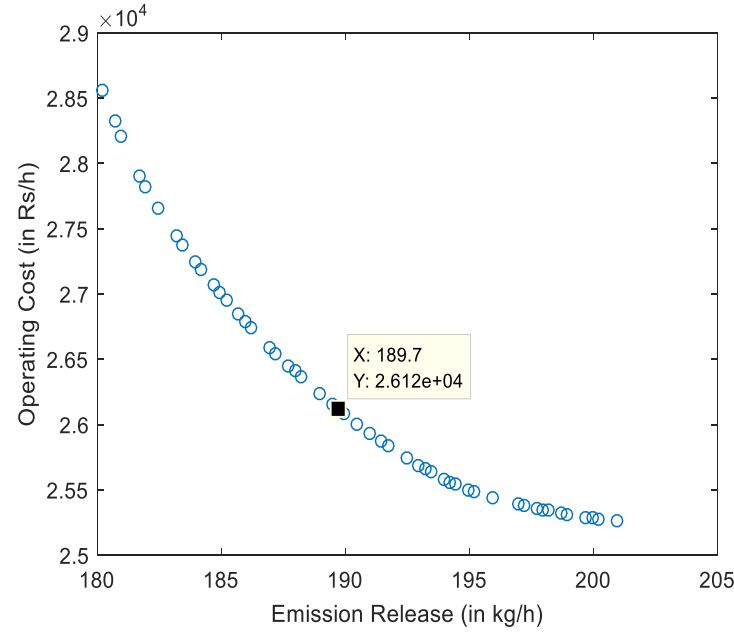

(a)

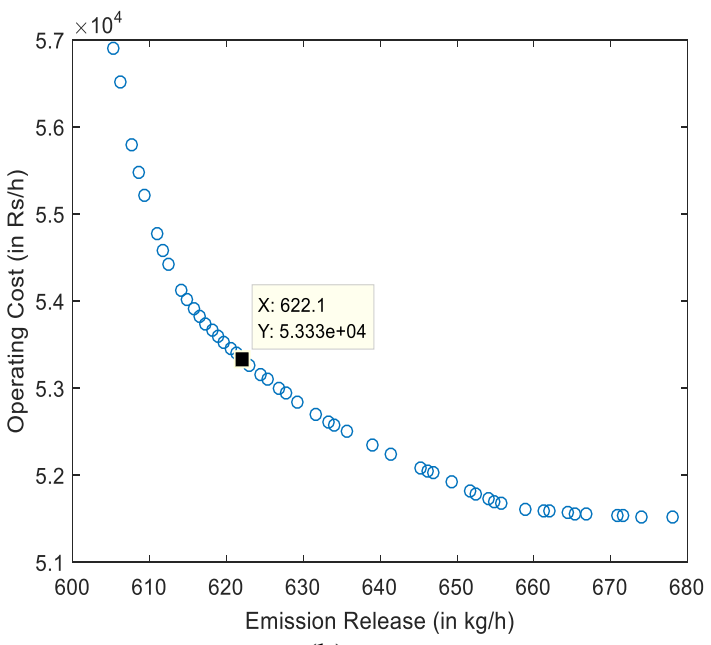

(b)

Figure 2. Pareto optimal front for case 3 for the load demands of $400 \mathrm{MW}$ and $900 \mathrm{MW}$

\section{CONCLUSIONS}

This paper solves an economic environmental dispatch (EED) problem considering solar PV, wind and thermal energy generators. The proposed EED problem is solved considering the thermal generators constraints such as ramp rate, valve point loading (VPL), and prohibited operating zones (POZs) effects. The operating cost minimization objective consists of costs due to solar PV, wind and thermal generators, and costs due to over and under-estimation of stochastic solar PV and wind power generations. Emission minimization objective is formulated by considering the power outputs from conventional thermal generators. The single objective optimization considering these two objectives is solved by using particle swarm optimization (PSO) and the multi-objective optimization problem is solved by using MO-PSO algorithm. The proposed approach has been tested on six unit test system. The results obtained from PSO are also compared with genetic algorithms (GA) and enhanced genetic algorithm (EGA). Incorporation of unit commitment in the proposed optimization problem is a scope for future research work.

\section{ACKNOWLEDGEMENTS}

This research work has been carried out based on the support of "Woosong University's Academic Research Funding - (2019-2020)".

\section{REFERENCES}

[1] S. M. M. Khormandichali and M. A. Kamarposhti, "Optimal placement of wind generation units in order to increase revenues and reduce the imposed costs in the distribution system considering uncertainty," International Journal of Electrical and Computer Engineering (IJECE), vol. 9, no. 6, pp. 4524-4539, Dec. 2019.

[2] R. Moreno, J. Obando and G. Gonzalez, "An integrated OPF dispatching model with wind power and demand response for day-ahead markets," International Journal of Electrical and Computer Engineering (IJECE), vol. 9, no. 4, pp. 2794-2802, Aug. 2019.

[3] R. A. Jabr and B. C. Pal, "Intermittent wind generation in optimal power flow dispatching," IET Generation, Transmission \& Distribution, vol. 3, no. 1, pp. 66-74, Jan. 2009.

[4] F. Hu, K. J. Hughes, D. B. Ingham, L. Ma and M. Pourkashanian, "Dynamic economic and emission dispatch model considering wind power under Energy Market Reform: A case study," International Journal of Electrical Power \& Energy Systems, vol. 110, pp. 184-196, Sep. 2019.

[5] M. Basu, "Economic environmental dispatch of solar-wind-hydro-thermal power system," Renewable Energy Focus, vol. 30, pp. 107-122, Sep. 2019.

[6] J. Jin, P. Zhou, C. Li, X. Guo, M. Zhang, "Low-carbon power dispatch with wind power based on carbon trading mechanism," Energy, vol. 170, pp. 250-260, Mar. 2019.

[7] R. K. Samal and M. Tripathy, "Cost and emission additionality of wind energy in power systems," Sustainable Energy, Grids and Networks, vol. 17, Mar. 2019.

[8] O. T. Altinoz, "The distributed many-objective economic/emission load dispatch benchmark problem," Swarm and Evolutionary Computation, vol. 49, pp. 102-113, Sep. 2019. 
[9] J. Xu, F. Wang, C. Lv, Q. Huang and H. Xie, "Economic-environmental equilibrium based optimal scheduling strategy towards wind-solar-thermal power generation system under limited resources," Applied Energy, vol. 231, pp. 355-371, Dec. 2018.

[10] E. E. Elattar, "Modified harmony search algorithm for combined economic emission dispatch of microgrid incorporating renewable sources," Energy, vol. 159, pp. 496-507, Sep. 2018.

[11] P. P. Biswas, P. N. Suganthan, B. Y. Qu and G. A. J. Amaratunga, "Multiobjective economic-environmental power dispatch with stochastic wind-solar-small hydro power," Energy, vol. 150, pp. 1039-1057, May 2018.

[12] J. Hetzer, D. C. Yu and K. Bhattarai, "An economic dispatch model incorporating wind power," IEEE Transactions on Energy Conversion, vol. 23, no. 2, pp. 603-611, Jun. 2008.

[13] I. G. Damousis, M. C. Alexiadis, J. B. Theocharis and P. S. Dokopoulos, "A fuzzy model for wind speed prediction and power generation in wind parks using spatial correlation," IEEE Transactions on Energy Conversion, vol. 19, no. 2, pp. 352-361, Jun. 2004.

[14] C. Chen, "Simulated annealing-based optimal wind-thermal coordination scheduling," IET Generation, Transmission \& Distribution, vol. 1, no. 3, pp. 447-455, May 2007.

[15] X. Liu, W. Xu, "Minimum emission dispatch constrained by stochastic wind power availability and cost," IEEE Transactions on Power Systems, vol. 25, no. 3, pp. 1705-1713, Aug. 2010.

[16] N. Saxena, S. Ganguli, "Solar and wind power estimation and economic load dispatch using firefly algorithm," Procedia Computer Science, vol. 70, pp. 688-700, 2015.

[17] P. M. Joshi and H. K. Verma, "An improved TLBO based economic dispatch of power generation through distributed energy resources considering environmental constraints," Sustainable Energy, Grids and Networks, vol. 18, Jun. 2019.

[18] S. S. Reddy and P. R. Bijwe, "An efficient optimal power flow using bisection method," Electrical Engineering, vol. 100, no. 4, pp. 2217-2229, Dec. 2018.

[19] Q. Tan, S. Mei, Q. Ye, Y. Ding and Y. Zhang, "Optimization model of a combined wind-PV-thermal dispatching system under carbon emissions trading in China," Journal of Cleaner Production, vol. 225, pp. 391-404, Jul. 2019.

[20] A. A. Eladl, A. A. E. Desouky, "Optimal economic dispatch for multi heat-electric energy source power system," International Journal of Electrical Power \& Energy Systems, vol. 110, pp. 21-35, Sep. 2019.

[21] S. S. Reddy, "Congestion multi-objective optimal power flow for a thermal-wind-solar power system techniques," Journal of Green Engineering, vol. 7, no. 4, pp. 451-476, 2017.

[22] J. D. Gomez, L. F. Gaitan and E. R. Trujillo, "Particle swarm optimization applied to economic dispatchs," IEEE Workshop on Power Electronics and Power Quality Applications, pp. 1-5, 2017

[23] D. B. Attous and Y. Labbi, "Particle swarm optimization based optimal power flow for units with non-smooth fuel cost functions," International Conference on Electrical and Electronics Engineering, pp. I-377-I-381, 2009

[24] C. A. C. Coello, "An introduction to multi-objective particle swarm optimizers," Soft Computing in Industrial Applications, vol. 96, pp. 3-12, 2011.

[25] M. A. Abido, "Multiobjective particle swarm optimization for optimal power Flow problem," Handbook of Swarm Intelligence, vol. 8, pp. 241-268, 2011.

[26] C. Palanichamy and K. Srikrishna, "Economic thermal power dispatch with emission constraint," Journal of Institution of Engineers, vol. 72, pp. 11-18, 1991.

[27] X. Li, W. Wang, H. Wang, J. Wu, X. Fan and Q. Xu, "Dynamic environmental economic dispatch of hybrid renewable energy systems based on tradable green certificates," Energy, vol. 193, Feb. 2020.

[28] M. T. Hagh, S. M. S. Kalajahi and N. Ghorbani, "Solution to economic emission dispatch problem including wind farms using Exchange Market Algorithm Method," Applied Soft Computing, vol. 88, Mar. 2020.

[29] M. Daneshvar, B. M. Ivatloo, K. Zare and S. Asadi, "Two-stage stochastic programming model for optimal scheduling of the wind-thermal-hydropower-pumped storage system considering the flexibility assessment," Energy, vol. 193, Feb. 2020.

[30] M. S. Javed, T. Ma, J. Jurasz and M. Y. Amin, "Solar and wind power generation systems with pumped hydro storage: Review and future perspectives," Renewable Energy, vol. 148, pp. 176-192, Apr. 2020. 